\title{
A High-Efficiency 1 MHz 65 W GaN-Based LLC Resonant DC-DC Converter
}

\author{
Ammar, Ahmed Morsi; Nour, Yasser; Knott, Arnold
}

Published in:

Proceedings of 2019 IEEE Conference on Power Electronics and Renewable Energy

Link to article, DOI:

10.1109/cpere45374.2019.8980041

Publication date:

2020

Document Version

Peer reviewed version

Link back to DTU Orbit

Citation (APA):

Ammar, A. M., Nour, Y., \& Knott, A. (2020). A High-Efficiency 1 MHz 65 W GaN-Based LLC Resonant DC-DC Converter. In Proceedings of 2019 IEEE Conference on Power Electronics and Renewable Energy (pp. 448-52). IEEE. https://doi.org/10.1109/cpere45374.2019.8980041

\section{General rights}

Copyright and moral rights for the publications made accessible in the public portal are retained by the authors and/or other copyright owners and it is a condition of accessing publications that users recognise and abide by the legal requirements associated with these rights.

- Users may download and print one copy of any publication from the public portal for the purpose of private study or research.

- You may not further distribute the material or use it for any profit-making activity or commercial gain

- You may freely distribute the URL identifying the publication in the public portal 


\title{
A High-Efficiency $1 \mathrm{MHz} 65 \mathrm{~W}$ GaN-Based LLC Resonant DC-DC Converter
}

\author{
Ahmed M. Ammar, Yasser Nour and Arnold Knott \\ Department of Electrical Engineering \\ Technical University of Denmark \\ Kongens Lyngby, Denmark \\ \{ammma, ynour, akn\}@elektro.dtu.dk
}

\begin{abstract}
This paper presents an LLC resonant DC-DC converter for single-phase offline converters. A $1 \mathrm{MHz} 400 \mathrm{~V}$ to 48 $\mathrm{V}$ prototype employing gallium nitride (GaN) switching devices is designed and implemented. A high-frequency magnetic material is used for the magnetic devices, with the resonant inductor integrated in the transformer. The converter operation is based on soft switching and achieves up to $65 \mathrm{~W}$ of output power with a peak efficiency of $96 \%$ at full-load. Inherent load regulation capability is demonstrated from 5 to $65 \mathrm{~W}$ of power with fixed switching frequency, while line regulation for 360 to $440 \mathrm{~V}$ input is verified with a frequency modulation range of 816 to $1256 \mathrm{kHz}$ respectively.
\end{abstract}

Keywords—resonant power conversion, dc-dc converters, offline converters, wide bandgap semiconductors, zero voltage switching (ZVS)

\section{INTRODUCTION}

PWM converters have been the primary candidate for switch-mode power supplies (SMPS) for years. They offer high efficiency and power quality with simple control. Nevertheless, their operation is mostly based on hard switching, which limits their switching frequencies to few hundred $\mathrm{kHz}$ for high-voltage converters, in order to reduce their switching losses. This in-turn results in the need for larger passive devices to process and deliver the power to the load. On the other hand, resonant converters allow for the utilization of soft-switching techniques through the intrinsic alternating behavior of the currents and voltages through the switches, which results in substantially lower switching losses, and enables the design for higher switching frequencies, and thus achieving higher power densities. This has led to the investigation of their adoption into different applications typically dominated by PWM converters [1], one of which is offline converters [2][3].

The conventional solution for single-phase offline converters is a two-stage structure, as shown in fig. 1. The first stage is an AC-DC power factor correction (PFC) rectifier followed by an energy storage capacitor to filter the $100 / 120 \mathrm{~Hz}$ frequency component. The second stage is a DC-DC converter which steps-down the DC-bus voltage to the voltage level that applies to the load characteristics. With the boost converter being the primary candidate for the PFC front-end converter, the typical bus voltage interfacing the two stages is around 380-400 $\mathrm{V}$, with the $100 / 120 \mathrm{~Hz}$ ripple on top, typically being $10 \%$ of the nominal bus voltage, which sets the specification for the lineregulation capability of the DC-DC stage.

This project has received funding from the European Union's Horizon 2020 research and innovation programme under grant agreement No 731466.

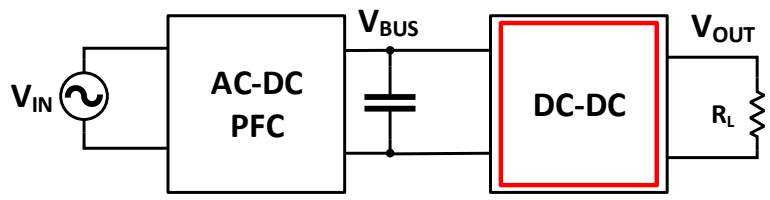

Fig. 1. Single-phase offline converters structure. The red box outlines the focus of this work.

This paper presents an LLC resonant converter solution for the DC-DC stage in offline converters. The LLC topology offers high-efficiency and inherent load regulation capability. It also offers soft-switching operation, thus allowing the design for high switching frequencies, which allows for achieving higher power densities. A $65 \mathrm{~W}$ prototype is designed and implemented for $48 \mathrm{~V}$ output voltage, which is a common voltage for several applications including computing power supply unit (PSU), telecom, power-over-Ethernet (PoE) and lighting.

This paper is organized as follows. Section II overviews the converter structure. The design procedure is illustrated in section III. Section IV covers the implementation process. Experimental results and waveforms are presented in section V. Eventually, conclusion is provided in section VI.

\section{CONVERTER Structure}

A resonant converter is comprised of two stages [4]-[6]. First, an inverter which incorporates a switch network that converts the $\mathrm{DC}$ input to a high frequency $\mathrm{AC}$, followed by a resonant tank that provides AC-AC gain. The second stage is a high-frequency AC-DC rectifier, which taps-off the energy in the resonant tank and delivers it to the load. Fig. 2 shows the LLC converter block diagram. The switch network can be configured as a half-bridge or a full-bridge arrangement. The resonant tank is comprised of the series connection of a resonant capacitor $C_{R E S}$, a resonant inductor $L_{R E S}$, and the magnetizing inductance of the rectifier transformer $L_{M}$. The

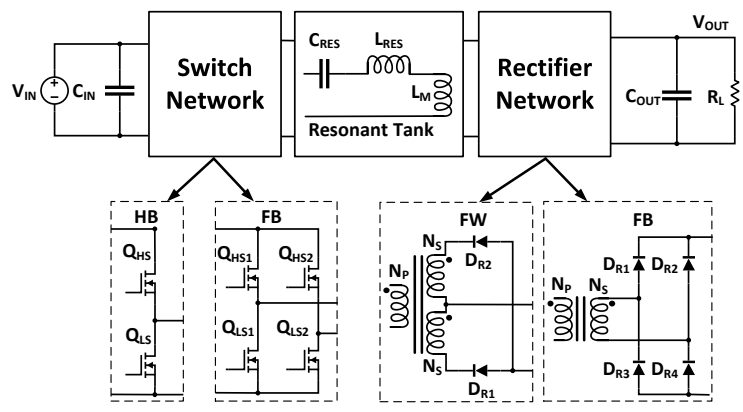

Fig. 2. LLC Converter block diagram. 
TABLE I. COMPARISON BETWEEN SWITCH AND RECTIFIER NETWORKS CONFIGURATIONS

\begin{tabular}{c|c|c|c|c}
\hline \multirow{2}{*}{ Parameter } & \multicolumn{2}{|c|}{ Switch Network } & \multicolumn{2}{c}{ Rectifier Network } \\
\cline { 2 - 5 } & HB & FB & FW & FB \\
\hline \hline Number of devices & 2 & 4 & 2 & 4 \\
\hline Voltage Gain & 0.5 & 1 & 1 & 1 \\
\hline Current Rating & x 2 & x 1 & x 1 & x 1 \\
\hline Voltage Rating & x 1 & x 1 & x 2 & x 1 \\
\hline Conduction Loss & x 2 & x 1 & x 0.5 & x 1 \\
\hline Winding Copper Loss & x 2 & x 1 & x 2 & x 1
\end{tabular}

rectifier can be implemented by a full-wave or a full-bridge configuration. Table I shows a comparison between the switch network and rectifier network configurations [7]. A half-bridge switch network would need to sustain double the current stress for the full-bridge network switches, but with half of the fullbridge number of devices. That results in reduced devices count at the expense of twice the total FETs conduction losses of the full-bridge, assuming the same power devices. In addition, a half-bridge voltage gain of one half requires half the transformer primary-winding number of turns for the same voltage gain and magnetic flux density, giving half the primarywinding resistance. However, the primary copper losses are still twice that of the full-bridge because of the four times squaredrms current. On the other hand, the full-wave rectifier has half the number of diodes compared to the full-bridge, with the same average current in the diode, resulting in half the diode conduction losses, but at the expense of twice the voltage rating. Additionally, a full-wave rectifier has two secondary windings, giving double the resistance for the same winding area, which results in twice the secondary-winding copper losses.

\section{Design Procedure}

\section{A. Specifications and Design Considerations}

Table II lists the design specifications for the presented converter, which target the low-mid power range applications. A switching frequency $(f s)$ of $1 \mathrm{MHz}$ is specified for the design, as it constitutes a good trade-off between the converter size and efficiency, with respect to the range of frequencies that the stateof-the-art magnetic materials allow for. With the specified power range, for which the primary current isn't high, a design choice of a half-bridge switch network is made, as the switches conduction losses and transformer primary winding copper loss are limited. On the other hand, a full-bridge rectifier configuration is chosen, since this simplifies the transformer design, and to ease the choice of the diodes with the availability of high-performance low-voltage Schottky diodes.

\section{B. Design Procedure}

The main design goal is to maintain zero-voltage switching (ZVS) within a frequency range that enables high efficiency across all line and load conditions. The design procedure illustrated in [7] is followed here. In order to maintain ZVS, the entire operation has to be within the inductive region of

TABLE II. DESIGN SPECIFICATIONS

\begin{tabular}{c|c}
\hline Parameter & Specification \\
\hline \hline Input Voltage & $400 \mathrm{~V}+10 \% 100 / 120 \mathrm{~Hz}$ ripple \\
\hline Output Voltage & $48 \mathrm{~V}$ \\
\hline Output Power & $65 \mathrm{~W}$ \\
\hline Efficiency & $\geq 95 \%$ at full-load \\
\hline
\end{tabular}

operation, where the resonant current lags the switching node voltage. From the specifications, the converter gain is calculated as follows.

$$
M=\frac{V_{\text {OUT }}}{V_{I N}}
$$

The converter gain is the product of the switch-network gain, the resonant-tank gain, and the transformer turns ratio. Considering a half-bridge for the switching network and a 4:1 turns ratio $(n$ $\left.=N_{S} / N_{P}\right)$ in the transformer, the required resonant tank gain is evaluated from

$$
M_{R E S}=\frac{M}{M_{H B} \cdot n}
$$

For a nominal input voltage of $400 \mathrm{~V}$ and $10 \%$ double the line frequency ripple, resulting in a line regulation range of 360 - 440 $\mathrm{V}$, the required range of resonant tank gain is calculated to 0.87 - 1.07 across the input-voltage range. The resonant-tank gain is the magnitude of the LLC resonant-circuit transfer function, which is a function of the loaded quality factor $\left(Q_{L}\right)$, the normalized switching frequency $\left(f_{n}\right)$, and the ratio of the total primary inductance to the resonant inductance $(k)$, and is evaluated by

$$
M_{R E S}=\frac{f_{n}{ }^{2}(k-1)}{\sqrt{\left(k \cdot f_{n}{ }^{2}-1\right)^{2}+f_{n}{ }^{2} \cdot\left(f_{n}{ }^{2}-1\right)^{2} \cdot(k-1)^{2} \cdot{Q_{L}}^{2}}}
$$

where

$$
\begin{gathered}
k=\frac{L_{R E S}+L_{M}}{L_{R E S}} \\
f_{n}=\frac{f_{S}}{f_{o}} \\
Q_{L}=\frac{\sqrt{L_{R E S} / C_{R E S}}}{R_{R E C}}
\end{gathered}
$$

with $f_{o}$ being the resonant frequency and $R_{R E C}$ being the reflected load resistance at the rectifier input, and are evaluated by

$$
\begin{gathered}
f_{o}=\frac{1}{2 \pi \sqrt{L_{R E S} \cdot C_{R E S}}} \\
R_{R E C}=\frac{8 R_{L}}{\pi^{2} n^{2}}
\end{gathered}
$$

The value for the parameter $k$ constitutes a trade-off between line-regulation capability through frequency modulation and efficiency. A low- $k$ value results in higher peaking of the resonant-tank gain curve for the same quality factor and resonant frequency, allowing for a higher gain variation within a narrow range of frequency modulation, and thus a better line-regulation capability. At the same time, a low- $k$ value is achieved with a smaller transformer magnetizing inductance $L_{M}$, which in-turn results in higher peak magnetizing current, causing increased conduction losses. For this design, a preliminary value of ten was chosen for the $k$ value in order to enable the integration of the resonant inductance $L_{R E S}$ into the transformer as the primary leakage inductance. This value also goes in hand with the choice of a half-bridge for the switch network, where the reduced 
circulating current limits the conduction losses. Circuit simulations are then used to verify the line-regulation capability for the specified line-input range within a reasonable frequency range, and accordingly high efficiency can be maintained.

Fig. 3 shows the resonant tank again across the normalized switching frequency for different values of the loaded quality factor and the chosen $k$ value. It can be observed that all load curves cross at $f_{n}=1$ and have a gain of unity. The curves peaks define the boundary between the capacitive and inductive regions of the resonant tank impedance across different loads. A maximum value for $Q_{L}$ needs to be specified and associated with the maximum load, while satisfying the gain requirements. The figure shows that a $Q_{L}$ value of 0.1 can reach the high gain value of 1.07, however it is less sensitive to frequency modulation in the above resonance $\left(f_{n}>1\right)$ region, thus reaching the low-gain value of 0.87 at a normalized frequency of $\sim 3.5$, causing extra switching losses in the switch network, in addition to increased $\mathrm{AC}$ conduction losses in the transformer. On the other hand, a higher $Q_{L}$ value of 0.75 reaches the minimum required gain at a lower normalized frequency $\sim 1.4$, but however fails to reach the maximum gain. A trade-off design choice of a maximum $Q_{L}$ of 0.22 is made. Using (6-8), the values for resonant tank components can be obtained.

\section{Simulation Results}

Fig. 4 shows simulation results of the presented converter switching-node voltage and resonant-tank current waveforms across different loads at a fixed switching frequency and constant DC output voltage of $1 \mathrm{MHz}$ and $48 \mathrm{~V}$ respectively. The figure shows that soft switching is achieved on the switching node across a wide load range of $5 \mathrm{~W}$ to $65 \mathrm{~W}$, while the resonant tank current scales with the output power. For the light-load range, the resonant current is observed to be mainly dominated by the transformer magnetizing current, which peaks at $\sim 350 \mathrm{~mA}$, resulting in a lower efficiency at light load, as the circulating energy is large relative to the energy delivered to the load. Light-load efficiency can be enhanced with a higher $k$ value (a higher magnetizing inductance $L_{M}$ ).

Fig. 5 shows simulation results for the switching-node voltage and resonant-tank current across different input voltages

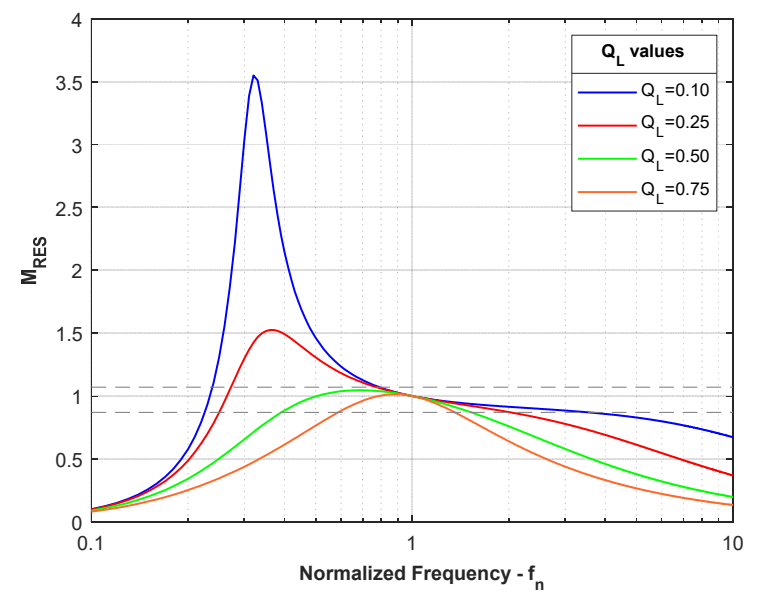

Fig. 3. Resonant tank gain as a function of the normalized switching frequency for different loads and $\mathrm{k}=10$ (Dashed lines represent required high and low gain limits).

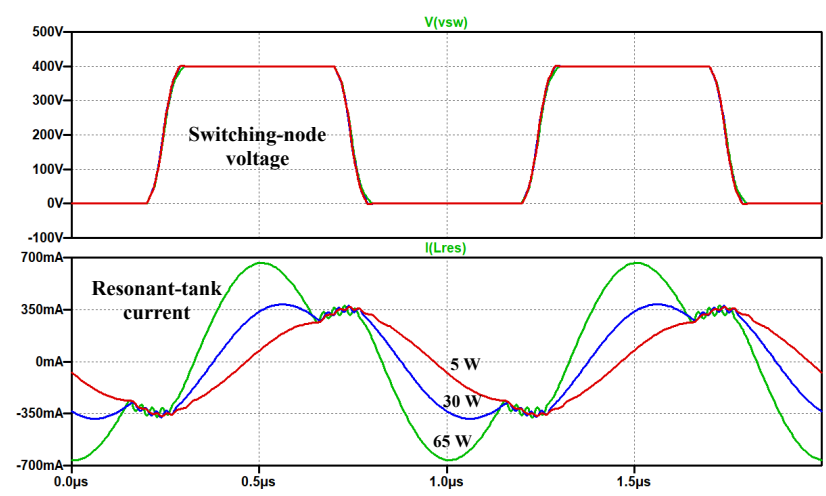

Fig. 4. Switching-node voltage and resonant-tank current across different loads (simulation results).

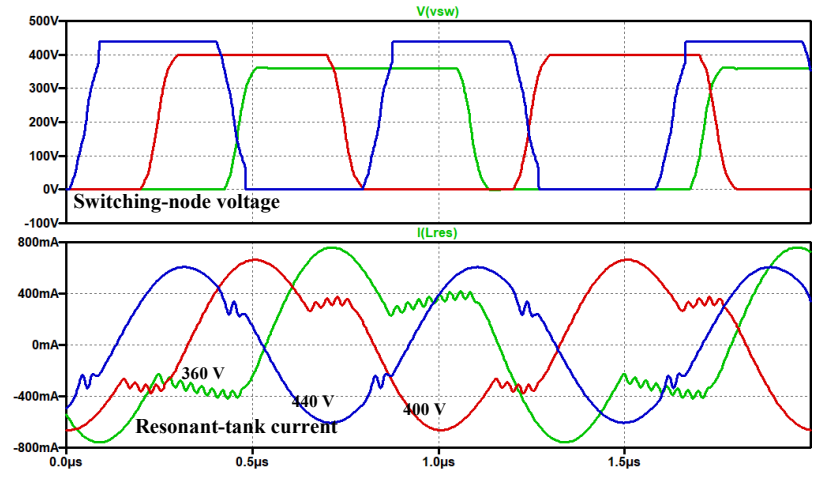

Fig. 5. Switching-node voltage and resonant-tank current across different input voltages (simulation results)

and switching frequencies, at a constant output voltage and power of $48 \mathrm{~V}$ and $65 \mathrm{~W}$ respectively. With a fixed duty cycle, full ZVS is achieved at the nominal input voltage with $1 \mathrm{MHz}$ switching frequency. Whereas partial soft-switching is observed at the $440 \mathrm{~V}$ input with $1.27 \mathrm{MHz}$ switching frequency, as a longer dead-time is needed. On the other hand, a short interval with diode-conduction is noticed at the $360 \mathrm{~V}$ input with 0.8 $\mathrm{MHz}$ switching frequency, where a reduced dead-time can achieve full ZVS. Accordingly, adaptive dead-time adjustment can result in the best efficiency across line and load ranges. With respect to the resonant tank current, the $360 \mathrm{~V}$ condition results in the highest peak current, where it is observed that transformer magnetizing current freewheels for longer time with no power delivered to the load, as operation is far from resonance. On the other hand, for the $440 \mathrm{~V}$ input with a switching frequency much closer to resonance, the current is almost sinusoidal and power is delivered to the output across almost the entire cycle.

\section{IMPLEMENTATION}

\section{A. Power Stage Design}

The ideal switch for the LLC converter is a one which allows for minimum conduction loss (low on-resistance) and maximum power transfer (short dead-time, low gate charge and output capacitance). Fig. 6 shows a comparison based on datasheet parameters between the best in-class switches figures of merit [8][9], where the gallium nitride $(\mathrm{GaN})$ devices outperform the silicon superjunction $(\mathrm{Si})$ and silicon carbide $(\mathrm{SiC})$ ones for this voltage and power range. Device 6 (GaN Systems GS66502B) 


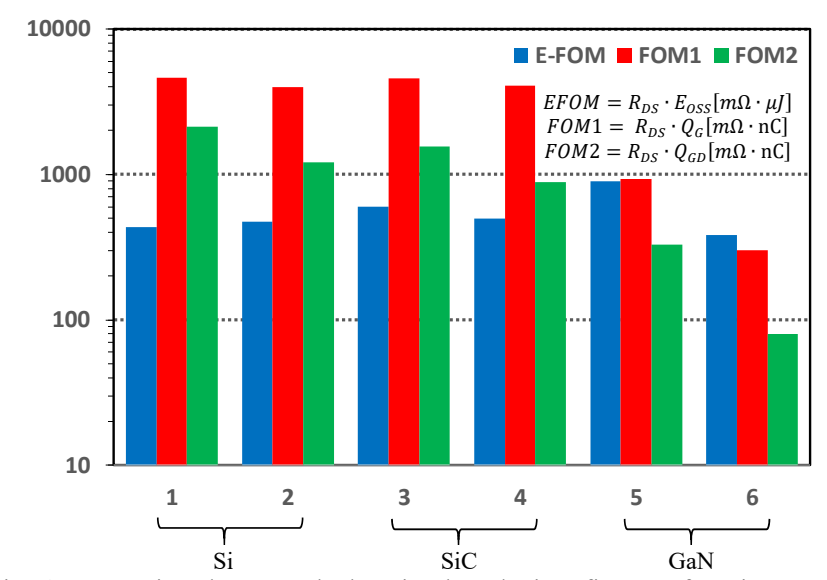

Fig. 6. Comparison between the best in-class devices figures of merit.

is used for the half-bridge switches realization. The switches gate driving circuit is comprised of a digital isolator (Si8610BC) and a gate driver (UCC27611) for each of the high-side and lowside switches. For the high-side driver supply, a bootstrap network of a diode (RFN1LAM6S) and a capacitor $(1 \mu \mathrm{F}$, ceramic X7R) is used. For the rectifier diodes, a low reverserecovery charge is key for achieving high efficiencies, as zerocurrent switching (ZCS) is not necessarily met across all line and load conditions. Schottky diodes offer near-zero reverserecovery charge, so the diode junction capacitance determines the switching loss. Accordingly, Schottky diodes with low capacitance for the rated voltage and current are chosen. The resonant capacitor is implemented using three parallel capacitors to reduce the effective series resistance (ESR). Table III shows a breakdown of the presented prototype bill of materials (BoM), including simulated and realized values.

\section{B. Magnetic Devices}

For this application with a high-frequency AC current, the choice of the magnetic material is of key importance. Fig. 7 shows a comparison of several high-frequency magnetic materials in terms of core losses at $1 \mathrm{MHz}$ [10][11]. The 3F46 material is chosen for the transformer core, as it shows the lowest core losses at the specified switching frequency. Regarding the core and winding structures, an EFD 25/13/9 core is used, and the primary and secondary windings are divided between the core halves and separated, in order to achieve a coupling coefficient aiding with the integration of the resonant inductor in the transformer through the primary leakage inductance, thus saving the space and cost for an additional component. The primary winding is realized using 26 turns of $60 \times 0.04 \mathrm{~mm}$ single-layer insulated Litz wire, while 6 turns of $255 \times 0.05 \mathrm{~mm}$ same-type wire is used for the secondary

TABLE III. PROTOTYPE BoM

\begin{tabular}{c|c|c|c}
\hline Component & Simulated & Prototype & Type \\
\hline \hline \multirow{2}{*}{$\mathrm{C}_{\mathrm{IN}}$} & \multirow{2}{*}{$10 \mu \mathrm{F}$} & $1 * 10 \mu \mathrm{F} / 450 \mathrm{~V}$ & Electrolytic \\
\cline { 3 - 4 } & & $3 * 0.1 \mu \mathrm{F} / 450 \mathrm{~V}$ & Ceramic (C0G) \\
\hline $\mathrm{Q}_{\mathrm{HS}}, \mathrm{Q}_{\mathrm{LS}}$ & & $\mathrm{GS} 66502 \mathrm{~B}$ & GaN Switches \\
\hline $\mathrm{C}_{\mathrm{RES}}$ & $1 \mathrm{nF}$ & $3 * 330 \mathrm{pF}$ & Ceramic (C0G) \\
\hline $\mathrm{L}_{\mathrm{RES}}$ & $15 \mu \mathrm{H}$ & $12.9 \mu \mathrm{H}$ & Custom Design \\
\hline $\mathrm{L}_{\mathrm{M}}$ & $135 \mu \mathrm{H}$ & $134.5 \mu \mathrm{H}$ & Custom Design \\
\hline $\mathrm{L}_{\mathrm{S}}$ & $7 \mu \mathrm{H}$ & $7.15 \mu \mathrm{H}$ & Custom Design \\
\hline $\mathrm{D}_{\mathrm{R} 1-\mathrm{D}_{\mathrm{R}}}$ & & PMEG6020ETP & Si Schottky \\
\hline $\mathrm{C}_{\mathrm{OUT}}$ & $0.1 \mu \mathrm{F}$ & $0.13 \mu \mathrm{F}$ & Ceramic (C0G) \\
\hline
\end{tabular}

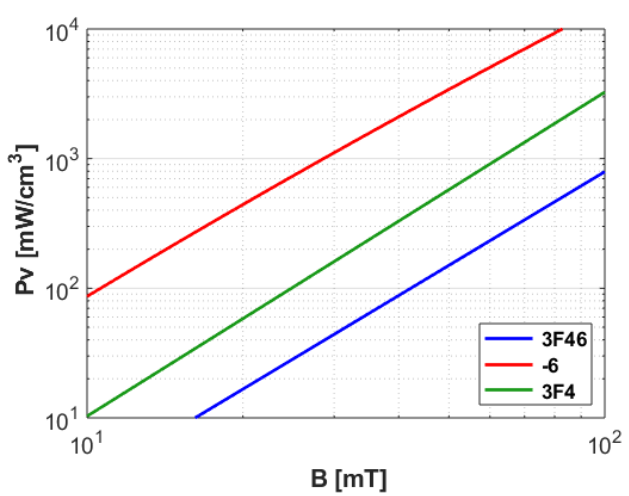

Fig. 7. Core power loss per volume $(P v)$ vs. magnetic flux density $(B)$ for different magnetic materials at $1 \mathrm{MHz}$.

winding. An air-gap of $0.21 \mathrm{~mm}$ achieved the desired magnetizing inductance. The air-gap is distributed equally between the inner and outer core legs, with clearance of windings turns in order to minimize the effect of the fringing flux and the losses associated with it. The transformer smallsignal characterization is conducted using a $40 \mathrm{~Hz}-110 \mathrm{MHz}$ precision impedance analyzer (Agilent Technologies 4294A). At $1 \mathrm{MHz}$, a total primary side inductance of $147.5 \mu \mathrm{H}$ and an ESR of $2.5 \Omega$ are obtained, with $12.9 \mu \mathrm{H}$ measured leakage inductance used towards the resonant tank inductance $L_{R E S}$, and leaving $134.6 \mu \mathrm{H}$ for the magnetizing inductance $L_{M}$. A secondary side inductance of $7.15 \mu \mathrm{H}$ is measured. That results in an effective transformer turns ratio of 4.34 .

\section{EXPERIMENTAL RESULTS}

\section{A. Lab Setup}

A thermal camera (Flir T650SC) continuously monitors the converter operation and a $2 \mathrm{GHz}$ scope (LeCroy WaveRunner 620Zi) displays the high-frequency signals, including the switching-node voltage, the resonant-tank current, and the gatesignals, where a $50 \mathrm{MHz}$ current probe (Hioki CT6700) captures the resonant-tank current waveform. A low-voltage DC power supply (Keysight B2962A) supplies the driving circuit, while a high-voltage power supply (Keysight AC6802A) is used for input-voltage supply, where another supply (Delta Elektronika SM400-AR-4) is stacked on top to source the $440 \mathrm{~V}$ input for the high-end of the line regulation test. A $120 \mathrm{MHz}$ dual-channel waveform generator (Keysight 33622A) generates the driving circuit signals, where the dead-time is adjusted and fixed at a point where soft switching is achieved and the average devices temperature is minimal. A DC electronic load (Itech IT8812B) acts as an active load for the circuit under test. Finally, a precision power analyzer (N4L PPA5530) is used for remote sensing and efficiency measurements.

\section{B. Measurements}

Accounting for the printed circuit board (PCB) layout parasitics, tolerances in the resonant-tank components values and temperature variations, the exact resonance frequency becomes subject to variations. Accordingly, an operating frequency of $1 \mathrm{MHz}$ guarantees below resonance operation at all conditions, yet maintaining the inductive mode of operation, which sustains soft switching and high efficiency across line and 


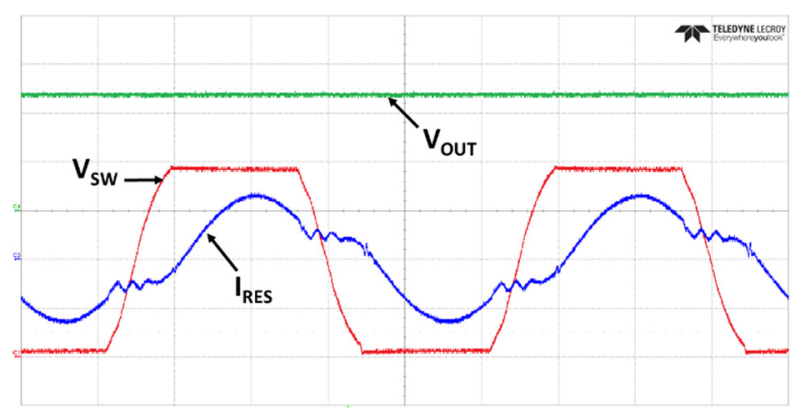

Fig. 8. Converter waveforms at $400 \mathrm{~V}$ input, $60 \mathrm{~W}$ and $1 \mathrm{MHz}$. $\left(V_{S W} 100 \mathrm{~V} / \mathrm{div}, I_{R E S} 500 \mathrm{~mA} / \mathrm{div}, V_{\text {OUT }} 20 \mathrm{~V} / \mathrm{div}\right.$ at $\left.200 \mathrm{~ns} / \mathrm{div}\right)$.

load variations. Fig. 8 shows a scope capture for the switchingnode voltage, resonant-tank current and the output voltage, with the nominal $400 \mathrm{~V}$ input voltage and $48 \mathrm{~V}$ output voltage, at 60 $\mathrm{W}$ of output power and $1 \mathrm{MHz}$ switching frequency. The figure illustrates the inductive mode of operation, with the resonant current lagging the switching node voltage, achieving full ZVS operation with an efficiency of $96 \%$.

Fig. 9 illustrates the inherent load-regulation capability of the LLC converter, showing the measured efficiency and output voltage across an output power range of $5 \mathrm{~W}$ to $65 \mathrm{~W}$, with a constant switching frequency of $1 \mathrm{MHz}$. The figure shows that high efficiency is achieved across the load range, with a peak efficiency of $96 \%$ at full load, while the maximum error on the nominal $48 \mathrm{~V}$ output voltage is $1.12 \%$ at the $5 \mathrm{~W}$ load. The reason for the low light-load efficiency is the dominance of the circulating energy of the freewheeling magnetizing current over the energy delivered to the load, as illustrated in fig. 4.

Fig. 10 illustrates the line regulation capability of the presented converter, where a fixed $48 \mathrm{~V}$ output voltage at a fixed load of $50 \mathrm{~W}$ is achieved through a frequency modulation range of 816 to $1256 \mathrm{kHz}$ for an input voltage range of $360 \mathrm{~V}$ to 440 $\mathrm{V}$ respectively, where the entire frequency range falls within the inductive region of operation and partial/full ZVS is maintained as illustrated in fig. 5 .

\section{CONCLUSION}

An LLC DC-DC converter for single-phase offline converters is presented. A $1 \mathrm{MHz}$ prototype employing gallium nitride $(\mathrm{GaN})$ switching devices is illustrated, where a high-

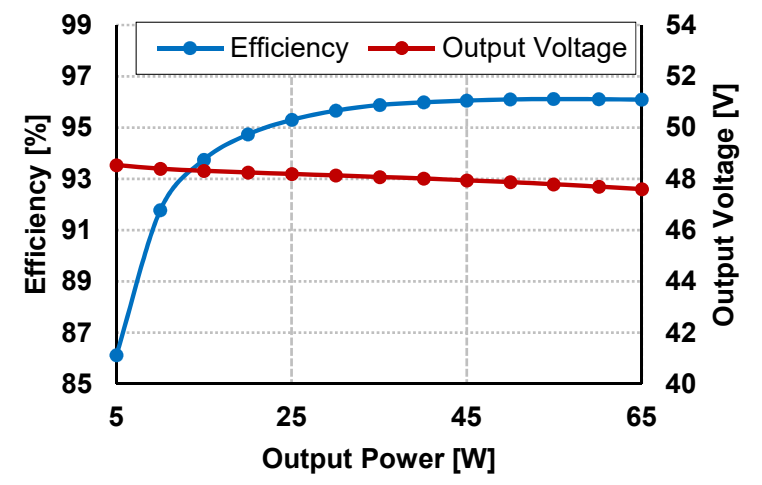

Fig. 9. Efficiency and output voltage vs. output power for $400 \mathrm{~V}$ input voltage at $1 \mathrm{MHz}$ operation.

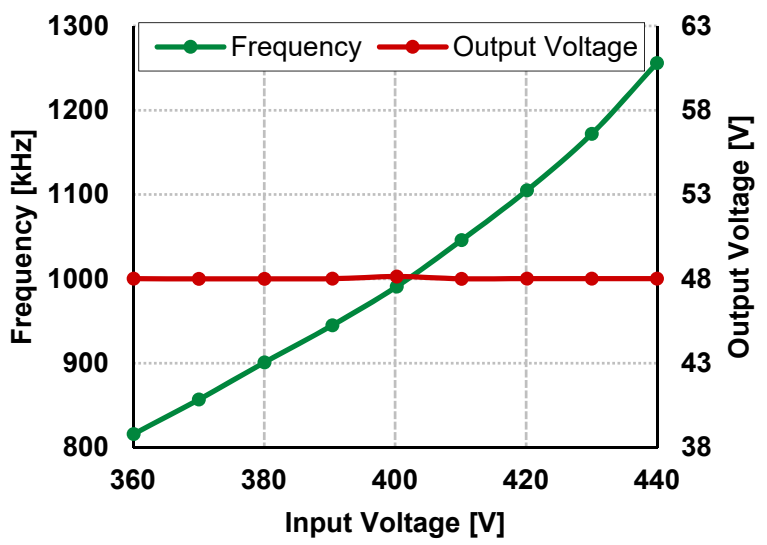

Fig. 10. Line regulation with frequency modulation at $50 \mathrm{~W}$ output power.

frequency magnetic material is used for the transformer design, with the resonant inductor integrated in the transformer through the primary leakage inductance. The experimental results show up to $65 \mathrm{~W}$ of output power with $96 \%$ efficiency at full-load. Inherent load regulation capability is demonstrated from 5 to 65 $\mathrm{W}$ of power, while line regulation for 360 to $440 \mathrm{~V}$ input is verified with frequency modulation.

\section{REFERENCES}

[1] J. M. Rivas, R. S. Wahby, J. S. Shafran and D. J. Perreault, "New Architectures for Radio-Frequency DC-DC Power Conversion," in IEEE Transactions on Power Electronics, vol. 21, no. 2, pp. 380-393, March 2006.

[2] A. M. Ammar, F. M. Spliid, Y. Nour and A. Knott, "A Series-Resonant Charge-Pump-Based Rectifier with Inherent PFC Capability," 2019 20th Workshop on Control and Modeling for Power Electronics (COMPEL), Toronto, ON, Canada, 2019, pp. 1-5.

[3] Bo Yang, F. C. Lee, A. J. Zhang and Guisong Huang, "LLC resonant converter for front end DC/DC conversion," APEC. Seventeenth Annual IEEE Applied Power Electronics Conference and Exposition (Cat. No.02CH37335), Dallas, TX, USA, 2002, pp. 1108-1112 vol.2.

[4] D. C. Marian, K. Kazimierczuk, Resonant Power Converters, 2nd edition. Wiley-IEEE Press, 2011.

[5] R. Mammano, Resonant Mode Converter Topologies-Additional Topics; Unitrode Design Seminars, 1990.

[6] Y. Nour, A. Knott, L. P. Petersen, "High frequency soft switching half bridge series-resonant DC-DC converter utilizing gallium nitride FETs", 2017 19th European Conference on Power Electronics and Applications EPE 2017 ECCE Europe, pp. 1-7, 2017.

[7] S. Abdel-Rahman, Resonant LLC Converter: Operation and Design, Infineon Technologies AN2012-09 V1.0, September 2012.

[8] E. Hoene, G. Deboy, C. R. Sullivan and G. Hurley, "Outlook on Developments in Power Devices and Integration: Recent Investigations and Future Requirements," in IEEE Power Electronics Magazine, vol. 5, no. 1, pp. 28-36, March 2018.

[9] Y. Nour, Z. Ouyang, A. Knott and I. H. H. Jørgensen, "Design and implementation of high frequency buck converter using multi-layer PCB inductor," IECON 2016 - 42nd Annual Conference of the IEEE Industrial Electronics Society, Florence, 2016, pp. 1313-1317.

[10] Ferroxcube material datasheet https://www.ferroxcube.com/upload/media/design/FXCStainmetzCoeffi cients.xls.

[11] Micrometals material datasheet https://micrometalsarnoldpowdercores.com/pdf/mix/Mix-6DataSheet.pdf 